\title{
Boundary-Layer Atmospheric Processes in Mountainous Terrain: Results from MATERHORN-X
}

\author{
Silvana Di Sabatino ${ }^{1}$
}

Received: 30 December 2015 / Accepted: 3 January 2016 / Published online: 12 February 2016

C) Springer Science+Business Media Dordrecht 2016

The study of atmospheric boundary-layer processes in complex terrain continues to be an active area of research considering its profound implications on numerical weather prediction (NWP). The improvement of current predictions at small scale and in complex environments is emerging as a result of increasing demands from society, particularly regarding the many applications involving mountain weather. Among them is the growth of urban settlements in the world located in complex terrain, and a large fraction of the world's population depends on a daily basis on good weather predictions at increased spatial and temporal resolution. The effective implementation of mitigation measures for reducing urban air pollution, prediction or management of extremes of urban heat island as well as defining the triggers for local climate rely upon the ability of models to predict flow that is often generated or modified by complex terrain. In addition, intensive weather phenomena near mountains are a safety hazard to aircraft and unmanned aerial vehicles, but they are often missed in predictions, either because of the inadequacy in resolution or the lack of the correct dynamics in the model. Improving mountain weather forecasts is the goal of the interdisciplinary Mountain Terrain Atmospheric Modeling and Observations (MATERHORN) program (2011-2016), as discussed by Fernando and Pardyjak (2013) and Fernando et al. (2015). The program was developed with four main pillars: modelling (MATERHORN-M), experiments (MATERHORN-X), technology (MATERHORN-T), and parametrizations (MATERHORN-P), all aimed at addressing new scientific challenges through dedicated field and laboratory studies, leading to the transfer of acquired knowledge for model improvements. Specifically, MATERHORN-X is at the core of the MATERHORN program. It was built upon two major field experiments carried out in September-October 2012 and in May 2013 at the Granite Mountain Atmospheric Science Testbed (GMAST) of the Dugway Proving Ground (DPG). The choice of the specific periods for the two campaigns was determined based on local climatology, with the purpose of studying two classes of processes, one focused on the effect of an isolated mountain (the

Silvana Di Sabatino

silvana.disabatino@unibo.it

1 Department of Physics and Astronomy Alma Mater Studiorum, University of Bologna,

Viale Berti Pichat 6/2, 40126 Bologna, Italy 
Granite Peak) on local meteorology under low synoptic forcing, and the other involving moderate or strong synoptic influence.

This special issue includes selected articles that report initial investigations of boundarylayer processes based on initial analyses of observations from MATERHORN X. The main authors and contributors were directly involved in the field campaigns.

The issue contains seven articles that underwent regular peer review. In the order of acceptance, the article by Grachev et al. explores characteristics of katabatic flows, and provides insights in to the understanding of pure katabatic flows and small-scale turbulence structures. It shows that the buoyancy term in the turbulent kinetic energy equations include extra terms that enhance or suppress turbulence. The nocturnal stable boundary layer is also the topic addressed by Serafin et al. who used MATERHORN data to assess a climatography of boundary-layer flows, based on a two-year archive of simulations from a high resolution operational mesoscale weather modelling system. Beyond the methodology proposed, this article deals with strong spatial gradients of main variables responsible for enhanced nocturnal mixing in transition areas from mountain walls to adjacent valleys. It also highlights the role of buoyancy in boundary-layer separation. The article by Hang et al. focuses on understanding soil moisture and evaporation processes, an important topic in the NWP model community considering their overall relevance to boundary-layer dynamics. This article clarifies the relationship between Bowen ratio, surface albedo, net radiation and soil moisture for desert areas, and presents a parametrization that has potential for implementation in NWP models. Oldroyd et al. highlight the importance of specific offline correction of sonic data when instruments are placed on steep ground by proposing an improvement for the standard planar-fit method for tilt correction. It is shown that the new method is an important step towards a robust procedure to be adopted for calculating fluxes, and in surface-energy-balance studies. Jensen et al. address the topic of the evening transition (i.e. reversal of slope and valley flows) by interpreting differences in terrain heterogeneity and its implications on flow transition. The article also investigates flow behaviour in the framework of Monin-Obukhov similarity theory, and deviations from it, to propose an explanation for counter-gradient fluxes often found in transitional periods. Dimitrova et al. give an example of current capabilities of the Weather Research Forecast model, predicting features of MATERHORN cases using default and refined parametrizations, and identifying the difficulties of capturing small-scale features. The volume concludes with the article by Leo et al. that provides an improvement to the classical relation for the dividing streamline height. This may have important consequences for improvement of local dispersion models in which the background flow is often parametrized in terms of input variables. The article also presents and discusses a dedicated experiment of smoke flow visualization in real conditions.

I believe this volume provides a stimulus for further exploration of the large MATERHORN dataset as well as parametrizations and understanding developed thereof. I thank Prof. Fernando from Notre Dame University (Indiana US) main lead of the MATERHORN program for first proposing the idea of this volume and the Editors Prof. Garratt and Prof. Fedorovich for the opportunity of hosting it in Boundary-Layer Meteorology. I also thank the Editorial staff of Springer for their prompt and efficient dealing of all publication formalities.

Acknowledgments Many thanks go to all authors who contributed to this volume and to the many discussions that occurred in the last couple of years during several meetings. This effort would not have been possible without the fund granted by the Office of Naval Research Award \# N00014-11-1-641 0709, Mountain Terrain Atmospheric Modeling and Observations (MATERHORN) Program. 


\section{References}

Fernando JF, Pardyjak ER (2013) Field studies delve into the intricacies of mountain weather. EOS 693 94(36):313-315

Fernando HJS, Pardyjak ER, Di Sabatino S, Chow FK, De Wekker SFJ, Hoch SW, Hacker J, Pace JC, Pratt T, Pu Z, Steenburgh JW, Whiteman CD, Wang Y, Zajic D, Balsley B, Dimitrova R, Emmitt GD, Higgins CW, Hunt JCR, Knievel JC, Lawrence D, Liu Y, Nadeau DF, Kit E, Blomquist BW, Conry P, Coppersmith RS, Creegan E, Felton M, Grachev A, Gunawardena N, Hang C, Hocut CM, Huynh G, Jeglum ME, Jensen D, Kulandaivelu V, Lehner M, Leo LS, Liberzon D, Massey JD, McEnerney K, Pal S, Price T, Sghiatti M, Silver Z, Thompson M, Zhang H, Zsedrovits T (2015) The MATERHORN—unraveling the intricacies of mountain weather. Bull Am Meteor Soc. ol 96:1945-1967 